\title{
Grammatical Impairment
}

National Cancer Institute

\section{Source}

National Cancer Institute. Grammatical Impairment. NCI Thesaurus. Code C92462.

A test that assesses a respondent's knowledge of grammar. It identifies respondents with specific language impairment (SLI) or other categories of language impairment. 